\title{
Early post-release movement of reintroduced lions (Panthera leo) in Dinokeng Game Reserve, Gauteng, South Africa
}

\author{
Sze-Wing Yiu ${ }^{1,3}$ \& Mark Keith ${ }^{2}$ \& Leszek Karczmarski ${ }^{1, *}$ \& Francesca Parrini ${ }^{3}$
}

\author{
${ }^{1}$ The Swire Institute of Marine Science, School of Biological Sciences, The University of Hong Kong, \\ Cape d'Aguilar, Shek O, Hong Kong \\ ${ }^{2}$ Centre for Wildlife Management, University of Pretoria, Private Bag X20, Hatfield, Pretoria 0028, \\ South Africa \\ ${ }^{3}$ Centre for African Ecology, School of Animal, Plant and Environmental Sciences, University of the \\ Witwatersrand, Private Bag 3, Wits 2050, South Africa \\ * Correspondence to: Leszek Karczmarski; leszek@hku.hk
}

\begin{abstract}
Reintroductions have been increasingly used in carnivore conservation. Animal movement influences fitness and survival and is the first behavioural response of reintroduced animals to 'forced dispersal' in a new habitat. However, information available on early post-release movement of reintroduced carnivores remains limited. We studied movements of 11 reintroduced lions (Panthera leo) in Dinokeng Game Reserve, South Africa, in their first season of release and investigated changes in movements over time. Movement patterns of lions were more diverse than expected and varied between sexes and individual groups. Some lion groups returned to the area surrounding the release site after initial exploration and avoided human settlements, suggesting that vegetation and human disturbances influenced dispersal upon release. Cumulative home range size continued to increase for all lions despite individual differences in movement patterns. We highlight the importance of considering the variation in individual-specific behaviour and movement patterns to assess early establishment and reintroduction success.
\end{abstract}

\section{Keywords}

CarnivoreReintroductionDispersalExplorationHome rangeSpace use

\section{Introduction}

Dispersal is a key process in animal movement ecology and can happen more than once at any stage in an animal's lifespan (Santini et al. 2013). It can be defined as an animal moving away from its natal or current home range to settle in another area (Bowler and Benton 2005). Dispersal behaviour allows animals to optimize their fitness and breeding opportunities with a trade-off between resource exploration and 
exploitation (Bonte et al. 2012). Before deciding to settle in a new area, animals typically perform exploratory movements that allow them to learn and compare habitat quality and distribution of competitors and predators (Delgado et al. 2009; Debeffe et al. 2013). However, exploration cost could be high because of the unfamiliarity with the environment, which leads to fitness reduction and high mortality risk due to misadventures (Bonte et al. 2012). Animals therefore need to balance the time and energy spent between exploration and exploitation to maximize benefits gained in dispersal.

While natural dispersal occurs in wild populations, early post-release movement of reintroduced animals can be viewed as 'forced dispersal' (Stamps and Swaisgood 2007). Reintroduction has been increasingly used to reestablish species in their former ranges in which they have been extirpated (Seddon et al. 2007; Armstrong and Seddon 2008). During a reintroduction, an animal bred in captivity or captured from a wild population is translocated to a new area (IUCN 1998). The process resembles natural dispersal as the animals have to balance the trade-off between exploration and exploitation in both situations, but forced dispersal implies bigger challenges and risks for reintroduced animals because they are forced to learn as efficiently and as quickly as possible, the landscape, environmental conditions and resource distributions that are completely new to them (Berger-Tal and Saltz 2014). Due to the lack of knowledge in landscape features, predators and competitors, mortality risk during exploration is even higher than in natural dispersals (Spinola et al. 2008), particularly for territorial species like lions (Panthera leo) which defend against intruders aggressively. In addition, homing behaviour is a common occurrence in reintroductions, when animals tend to travel towards the direction of their capture sites upon release (Rogers 1988). Such behaviour has been interpreted as a rejection to the forced dispersal and typically results in lowsite fidelity, i.e. animals are unwilling to settle in the new area (Miller et al. 1999). Understanding movement patterns in the early post-release period is thus critical for the survival and reestablishment of reintroduced animals (Preatoni et al. 2005; Berger-Tal and Saltz 2014).

Large carnivores are frequent subjects of reintroductions due to their predisposed risk of extirpation because of high ecological demands, sensitivity to habitat loss and high potential for human conflicts (Woodroffe 2000; Cardillo et al. 2004; Hayward and Somers 2009). In South Africa, there has been an increase in establishment of small reserves and demand for reintroducing flagship carnivores including lions, leopards (Panthera pardus), cheetahs (Acinonyx jubatus), wild dogs (Lycaon pictus) and spotted hyaenas (Crocuta crocuta) in recent years (Hayward et al. 2007a, b). Most studies on reintroduced carnivores have focused mainly on population control, inbreeding, diseases and human-wildlife conflicts (Ferreira and Hofmeyr 2013; Miller and Funston 2014), while information on post-release movement behaviour is limited (Hayward et al. 2007b; Hunter et al. 2007). Post-release movement pattern allows us to understand the exploration-exploitation trade-off of reintroduced animals during establishment stage and individual variation in movement strategies in adapting to a new environment, which can be used as a tool to assess establishment success (Berger-tal and Saltz 2014). On the other hand, individual movement decisions do not only affect individual fitness but also the behaviour and the interactions of conspecifics and sympatric species (Fortin et al. 2005), which could ultimately have important implications on community structure and population dynamics (Hawkes 
2009; Morales et al. 2010). Studying individual animal movement, particularly of large mammalian species that are able to undertake long-distance movement and have large home ranges, is therefore crucial in understanding their spatial dynamics and broader population processes (Tilman and Kareiva 1997).

Our study investigated space use and movement patterns of reintroduced lions subjected to forced dispersal during their early post-release period and to assess the potential of using movement patterns to identify successful reintroductions. Directions of movements, daily movement rates and distances from release sites were compared over time, as well as animal locations in relation to human settlements. We expected movement rates to be highest upon release, decrease over the study period and eventually stabilize, together with an initial increase in distances from the release site during exploration and stabilization or reduction when the animals had settled. An increase in distances from buildings over time was expected in avoidance to human disturbances, a factor found to influence carnivore behaviours in various studies (Kerley et al. 2002; Ngoprasert et al. 2007). We also compared movements at different times of the day to test if forced dispersal increases diurnal activities of lions due to the need to explore the environment and avoid previously released conspecifics. Lastly, we constructed utilization distributions, a statistical representation of home ranges, and expected a positive relationship between movement rates and cumulative home range sizes for as long as the lions still display exploratory behaviours.

\section{Materials and methods}

\section{Study area}

The study was undertaken in the entirely fenced $185-\mathrm{km}^{2}$ Dinokeng Game Reserve (DGR), situated in the Gauteng and Limpopo Province in South Africa (25.370634 $\mathrm{S}, 28.379726^{\circ} \mathrm{E}$, Fig. 1). DGR is located within the savannah biome, with mixed Bushveld, Kalahari thornveld, and sourish mixed Bushveld representing major vegetation units (Mucina and Rutherford 2006). Altitude of the reserve varies from $1100 \mathrm{~m}$ in the southeast to $1200 \mathrm{~m}$ in the northwest. Average annual rainfall is $674 \mathrm{~mm}$ with distinct wet (October-April) and dry (May-September) seasons (New et al. 2002). The Pienaars River in the west of DGR is joined by the Kaallaagte Spruit and the Boekenhout Spruit, providing perennial source of water in the reserve together with more than 40 natural and artificial dams (Fig. 1; unpublished report, Contour Project Managers CC 2009). 


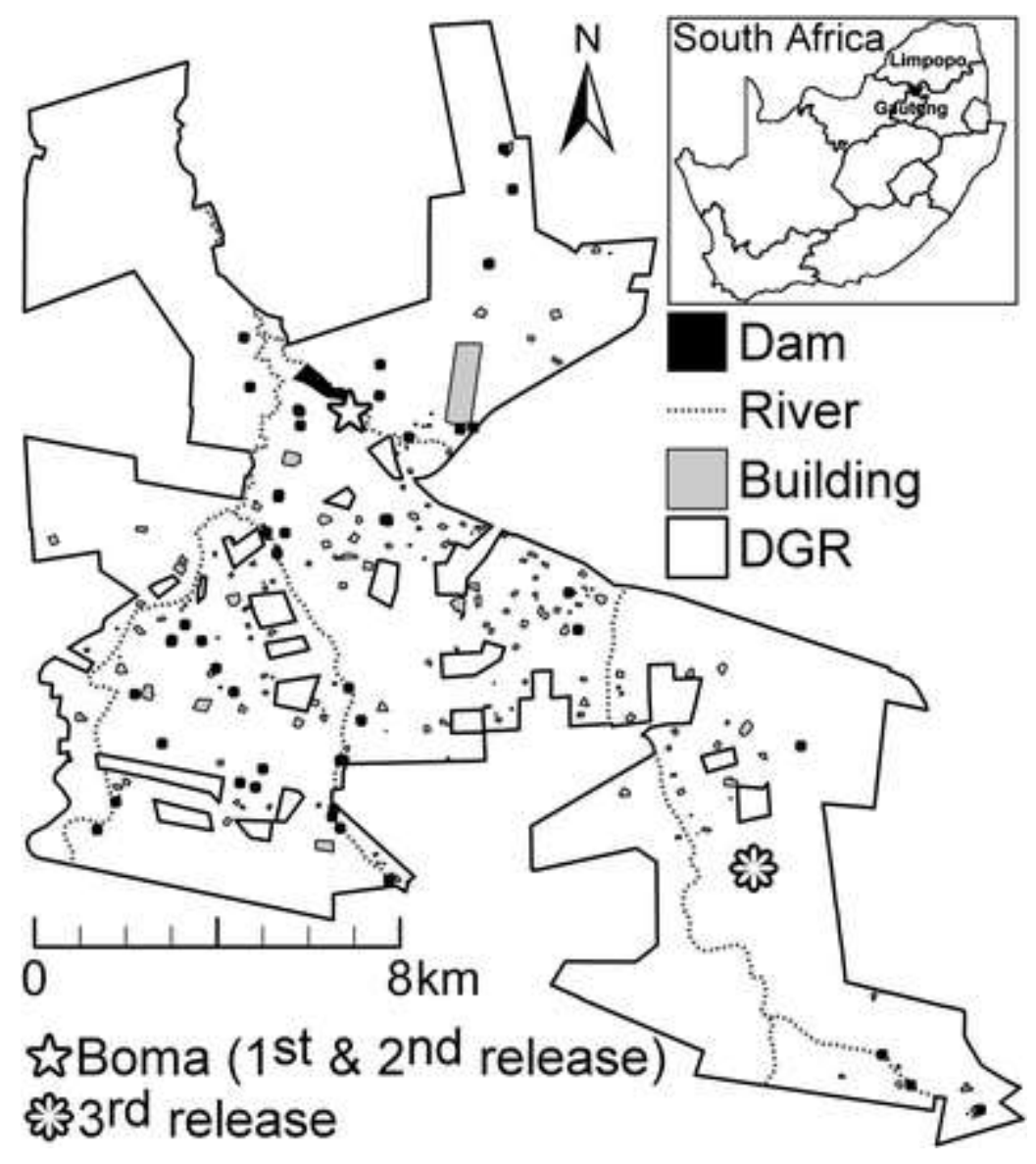

Fig. 1, Study area, the Dinokeng Game Reserve (DGR), with indicated locations of boma and release sites. Location of DGR in South Africa (inset map)

DGR was officially opened in 2011 with the main aim of promoting eco-tourism. It is the first initiative in South Africa to involve provincial government and over 250 private landowners in removing fences and incorporating their land into a larger reserve. DGR is still at a stage of expansion and is expected to span an area of $1200 \mathrm{~km}^{2}$ after completion (unpublished report, Contour Project Managers CC 2009). More than 15 species of antelopes can be found in DGR; the most abundant are blue wildebeest (Connochaetes taurinus; 1635), impala (Aepyceros melampus; 1239), Burchell's zebra (Equus quagga burchelli; 818) and blesbock (Damaliscus dorcas phillipsi; 686) (unpublished DGR aerial census data 2012). Prior to the reintroduction of lions, leopard and brown hyaena (Hyaena brunnea) were the only large carnivores confirmed to exist, but sightings of leopards were less than once per year (unpublished report, Contour Project Managers CC 2009).

\section{Lion reintroductions and data collection}

Eleven lions, four males and seven females of different ages and genetic relatedness, were introduced in three different release events between 2011 and 2013 (Table 1). All information on the reintroductions was collected from Dinokeng Game Reserve Management Association (DGRMA), the official management company of DGR. Lions were captured and translocated from Welgevonden Game Reserve, Pilanesberg Game Reserve, Madikwe Game Reserve and Tembe Elephant Park. Individuals released together were kept in a $45 \times 85 \mathrm{~m}$ boma (Fig. 1) 
for 1 month prior to the release. Keeping the animals in captivity before release is a procedure widely recommended in carnivore reintroduction to facilitate recovery from the shock of capture and translocation and to allow for acclimation to a new environment and enhance bonding formation between unrelated individuals (Miller et al. 2013). Lions in the first and second reintroduction were released directly from the boma, while animals in the third reintroduction were first translocated from the boma to the southeast of the reserve and released (Fig. 1). The boma was situated next to the biggest dam in the reserve surrounded by dense reed beds (Phragmites australis) and floodplain and riparian vegetation complex that is also the major vegetation type at the release site of the third reintroduction located closely to the river. Females in the first and second releases were injected with contraceptives as a management decision by DGRMA.

Table 1. Details of the lions reintroduced into Dinokeng Game Reserve during three reintroduction events between 2011 and 2013

\begin{tabular}{|c|c|c|c|c|}
\hline $\begin{array}{l}\text { Date of } \\
\text { release }\end{array}$ & $\begin{array}{l}\text { Group structure after } \\
\text { release (group id: lion id) }\end{array}$ & $\begin{array}{l}\text { Age in years at } \\
\text { release }\end{array}$ & $\begin{array}{l}\text { Genetic } \\
\text { relationship }\end{array}$ & Capture site \\
\hline \multirow{2}{*}{$19 / 10 / 2011$} & Males-release $1: M 1^{*}, M 2$ & 2.5 & Brothers & $\begin{array}{l}\text { Welgevonden Game } \\
\text { Reserve }\end{array}$ \\
\hline & Females-release $1: F 1^{*}, F 2$ & 2 & Sisters & \\
\hline \multirow{2}{*}{$14 / 11 / 2011$} & Males-release $2: M 3^{*}, M 4$ & 2 & Brothers & $\begin{array}{l}\text { Pilanesberg Game } \\
\text { Reserve }\end{array}$ \\
\hline & Females-release 2: $F 3^{*}, F 4$ & 2 & Sisters & $\begin{array}{l}\text { Madikwe Game } \\
\text { Reserve }\end{array}$ \\
\hline \multirow{2}{*}{$02 / 11 / 2013$} & Females-release $3: F 5^{\star}, F 6$ & 5 & Sisters & $\begin{array}{l}\text { Tembe Elephant } \\
\text { Park }\end{array}$ \\
\hline & Lone female-release $3: F 7^{*}$ & 2 & Daughter of F5 & \\
\hline
\end{tabular}

Asterisk indicates individual group members with GPS locations data used to representing the group

All lions were fitted with satellite collars manufactured by Africa Wildlife Tracking (Pretoria, South Africa) that recorded GPS locations at regular intervals (first and second release every $4 \mathrm{~h}$; third release every $5 \mathrm{~h}$ ). The locations were sent via satellite to an online centralized database and downloaded from there. To document group structure and interactions between groups that could affect their movements, sightings information were obtained from ranger and landowner reports and, where possible, direct observation in the field. We obtained ArcGIS shapefiles of the rivers from unpublished report, Contour Project Managers CC (2009) and created shapefiles of dams and buildings using satellite image from Google Earth (2005). All shapefiles were projected as UTM WGS1984 35S coordinate system in ESRI ${ }^{\circledR}$ ArcMap $^{\mathrm{TM}}$ 9.3.1.

\section{Data analyses}

We defined early post-release period as the first wet season (October-April; first and second release 2011-2012; third release 2013-2014) after release to control for potential seasonal effects on lion movements due to seasonal distribution of prey (Hunter 1998; Hayward et al. 2009). Movement was analysed as the movements of groups, based on association of animals after release (Table 1). GPS locations of the group member that had the most regular fixes were used, and movements were 
compared between each 30-day period. Six time periods were included for all groups except lions in the second release that had five time periods only, as they were released in mid-November 2011.

Distance and bearing between consecutive locations, bearing between release and capture site of each group and distance between each location and the release site and nearest buildings were calculated using Hawth's Analysis Tools 3.27 (Beyer 2004) and $\mathrm{ESRI}^{\circledR}$ ArcMap $^{\mathrm{TM}}$ 9.3.1. Distances between locations were separated into six different time slots and defined as 0400-0800 hours (sunrise), 0800-1200 hours (morning), 1200-1600 hours (afternoon), 1600-2000 hours (sunset), 2000-0000 hours (night) and 0000-0400 hours (midnight) for the lions in first and second release. Because of the 5-h recording interval, locations for lions in the third release were taken at different time in each day, and we defined 0400-0900 hours as sunrise, 0800-1300 hours as morning, 1200-1700 hours as afternoon, 1500-2000 hours as sunset, 1900-0000 hours as night and 2300-0400 hours as midnight. Daily distances travelled were calculated by summing up the distances between locations in each day. Distances to release sites and buildings were averaged across each day, using only the first location when animals remained stationary for more than one location (when distance to the next location was $<100 \mathrm{~m}$, a distance used to identify GPS clusters of potential feeding sites of carnivores; Tambling et al. 2010; Wilmers et al. 2013) to prevent pseudo-replication.

Rayleigh test of uniformity (one-sample test for mean angles, Zar 1984) was performed to test the bearings of movement against random distribution separately for each 30-day period using R 3.1.1 (R Core Team 2015) and the R package 'CircStats' (Lund and Agostinelli 2014). Homing behaviour was assumed to be present if the direction from release to capture site fell within the confidence interval of significant direction of travel.

Daily distances travelled were square root transformed and compared between 30 day periods for each lion group using one-way analysis of variance (ANOVA) with post hoc Tukey's HSD test. Due to violation of model assumptions of normality and equal variances even after data transformation, comparison of distances travelled at different times of day and distances between locations and release site and nearest building were done using Kruskal-Wallis non-parametric ANOVA with post hoc Bonferroni-Dunn test. Apart from the 30-day periods, distances to buildings were also compared between weekdays (Monday to Thursday) and weekends (Friday to Sunday; Fridays were included into weekends because of local customary reasons) using Mann-Whitney $U$ test, because human disturbances might be higher on weekends due to higher number of visitors. Kruskal-Wallis non-parametric ANOVA compares data by ranks; therefore, results were reported in box plots showing medians, minimum and maximum values and first and third quartile (Kruskal and Wallis 1952). All statistical tests were performed in R 3.1.1 (R Core Team 2015).

The k-LoCoH (local convex hull; Getz and Wilmers 2004) method was used to construct $50 \%$ core and $95 \%$ full home range utilization distributions using $R$ package 'adehabitat' in R2.13.0 (Calenge 2006). Values for $k$ were selected as $n / 2---\sqrt{ }$ 
, where $n$ equals number of locations (Getz and Wilmers 2004). To investigate the process of expansion and stabilization of home ranges over time, we constructed cumulative utilization distributions by adding the locations of the previous time period, i.e. number of locations was cumulated over time.

\section{Results}

\section{Post-release group structure and survival}

Lions kept in boma and released together showed varied post-release association (Table 1). In the first and second release, the animals split into pairs of brothers and sisters, and these pairs remained together throughout the early post-release period. In the third release, the youngest females roamed alone most of the time but occasionally joined the two adult females that remained associated. Movement analyses were therefore done separately for these six groups (males-release 1, females-release 1 , males-release 2 , females-release 2 , females-release 3 , lone female-release 3).

The females-release 2 and one of the males from males-release 2 were killed in their seventh and fourth month of release, respectively, by the males-release 1.

Consequently, from the fifth time period, movement of males-release 2 represented only the one survived individual.

\section{Direction of movements and homing behaviour}

None of the lions were found to have movement directions different from random (Rayleigh test of uniformity, $p \geq 0.15$ ). Consequently, no lions were moving towards a specific direction, and no homing behaviour was detected.

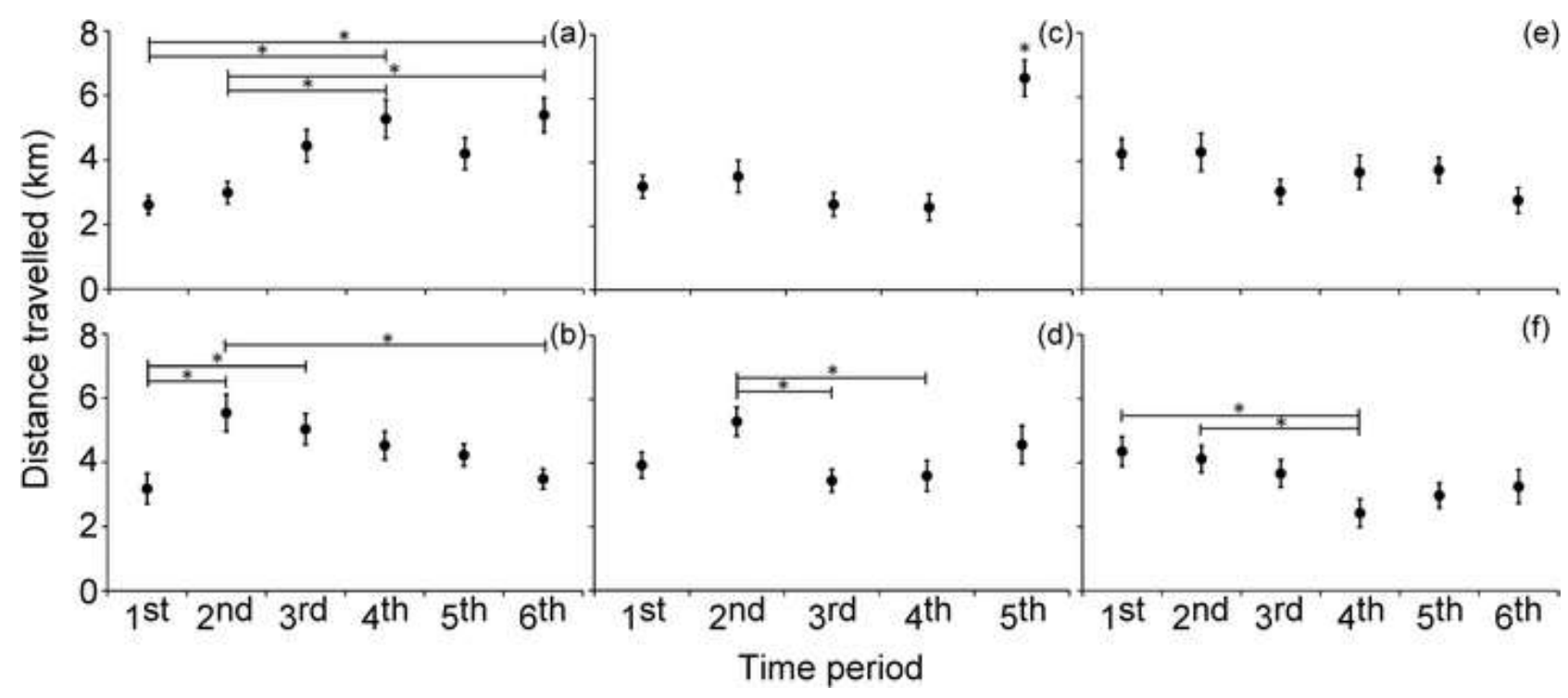

Fig. 2. Average daily distance travelled by lions (mean $\pm \mathrm{SE}$ ) during early post-release period in 2011-2012 and 2013-2014 in the Dinokeng Game Reserve, South Africa. Asterisk indicates significant difference. a Males-release 1, b females-release 1, c males-release 2, d females-release 2 , e females-release 3 and $\mathbf{f}$ lone female-release 3 


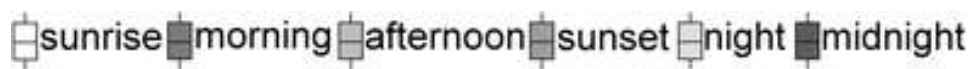
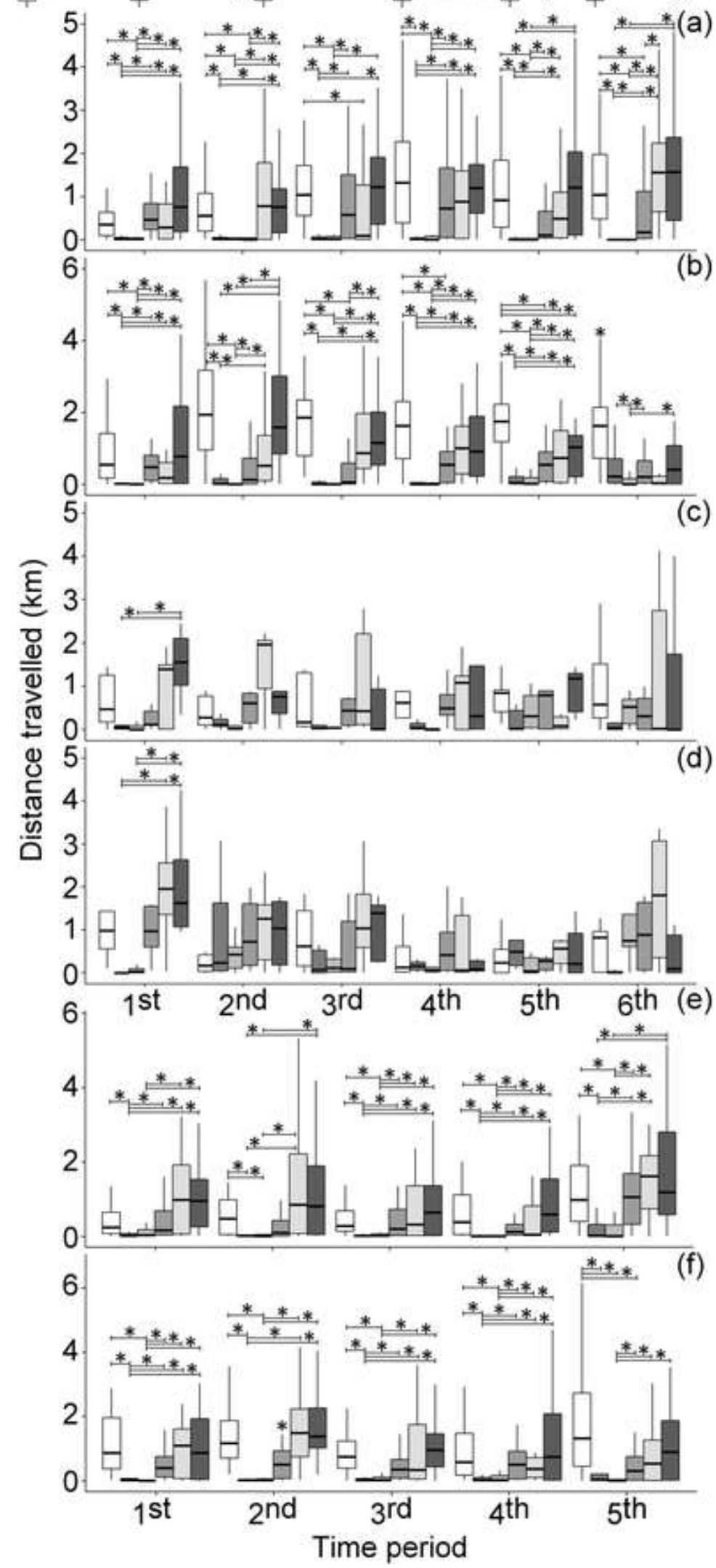

Fig. 3. Average distance travelled by lions in different time of a day during early post-release period in 2011-2012 and 2013-2014 in the Dinokeng Game Reserve, South Africa. Box plot shows median, minimum and maximum values, and first and third quartile. Asterisk indicates significant difference. a 
Males-release 1, b females-release 1, c females-release 3, d lone female-release 3, e males-release 2 and $\mathbf{f}$ females-release 2

\section{Daily movement rate}

Average daily distance travelled by lions ranged from $2.42 \pm 0.44$ to $6.64 \pm 0.57 \mathrm{~km}$ (mean \pm SE, Fig. 2). Movements through time varied greatly between groups, with an increase in distance travelled observed in male pair-release 1 in fourth time period (one-way ANOVA, $F_{5,174}=5.49, p<0.001$; Tukey's HSD test, $p<0.05$ ) and femalesrelease 1 in second time period (one-way ANOVA, $F_{5,174}=4.01, p<0.01$; Tukey's HSD test, $p<0.05)$. On the contrary, females-release 2 and lone female-release 3 significantly reduced their distance travelled in third (one-way ANOVA, $F_{4,145}=2.68$, $p<0.05$; Tukey's HSD test, $p<0.05$ ) and fourth time periods (one-way ANOVA, $F_{5,173}=2.94, p<0.05$; Tukey's HSD test, $p<0.05$ ), respectively. Movement of these four lion groups stabilized after the initial increases and decreases. A significant increase in distance travelled was found in males-release 2 in fifth time period after one member was killed (one-way ANOVA, $F_{4,144}=11.92, p<0.001$; Tukey's HSD test, $p<0.05$ ), while females-release 3 had similar travel distances throughout the early post-release period.

\section{Movement rates at different times of the day}

Lions moved different distances during different times of the day (Fig. 3) and in general moved more at sunrise, night and midnight. The least movements occurred in the morning and afternoon. The animals in the first and second release travelled significantly less in the morning and afternoon than in other times of the day (Kruskal-Wallis test, $x^{2}>46.73, d f=5, p<0.001$; Bonferroni-Dunn test, $p<0.05$ ) during which individual variation was low throughout the entire early post-release period (Fig. 3).

In comparison, lions in the last release travelled significantly less in mornings and afternoons only in the first time period (Kruskal-Wallis test, $x^{2}>23.28, d f=5$, $p<0.001$; Bonferroni-Dunn test, $p<0.05$ ). Their movement remained similar through the day from second time period onwards.

\section{Distance from release site}

Variation among lions in dispersal behaviour upon releases was large. Medians of distances from release site ranged from 1.50 to $7.18 \mathrm{~km}$, first quartile from 0.81 to $6.68 \mathrm{~km}$ and third quartile from 1.68 to $8.18 \mathrm{~km}$ (Fig. 4), and in all cases but one (females-release 2), these distances differed between time periods (Kruskal-Wallis test, males- and females-release 1 and $3: x^{2}>40.77, d f=5, p<0.001$; males-release $\left.2: x^{2}=90.06, d f=4, p<0.001\right)$, but what varied was the pattern of these changes. Two lion groups (males-release 2, lone female-release 3 ) dispersed, resulting in an increase in distance from the sites through time, while three groups (males-release 1 , females-release 2 and females-release 3 ) travelled back to the area of release sites after initial dispersal, which led to a decrease in distances after an initial increase. 


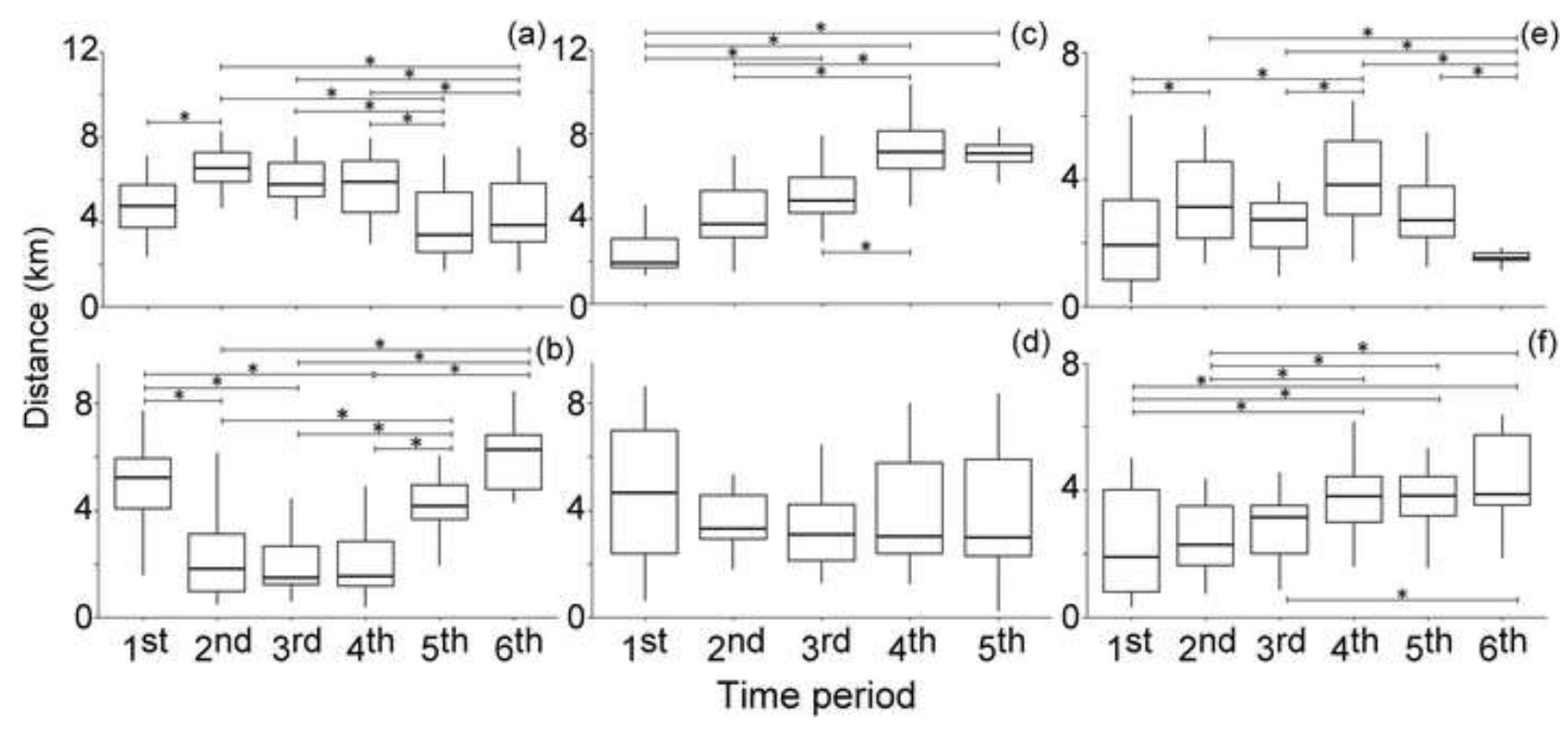

Fig. 4. Average daily distance of lions from release sites during early post-release period in 20112012 and 2013-2014 in the Dinokeng Game Reserve, South Africa. Box plot shows median, minimum and maximum values, and first and third quartile. Asterisk indicates significant difference. a Males-release 1, $\mathbf{b}$ females-release 1, c males-release 2, $\mathbf{d}$ females-release 2, e females-release 3 and $\mathbf{f}$ lone female-release 3

\section{Distance to buildings}

Distances to nearest buildings significantly differed between weekdays and weekends only in certain time periods (males-release 1: first time period, femalesrelease 1 and males-release 2: third time period, females-release 2: first and third time period, females-release 3: fifth time period, lone female-release 3: sixth time period; Mann-Whitney $U$ test, $U>35, p<0.05$ ).

The effects of the presence of buildings on lion movements changed through time. The distance from buildings kept by males increased significantly over time in both weekdays and weekends (Kruskal-Wallis test, males-release $1: \chi^{2}>44.32, d f=5$, $p<0.001$; males-release 2: $x^{2}>29.25, d f=4, p<0.001$; Bonferroni-Dunn Test, $p<0.05$ ) (Fig. 5). Among females, some retained a similar distance to buildings during weekdays throughout the entire period (Kruskal-Wallis test, females-release 2: $x^{2}=6.68, d f=4, p=0.15$; lone female- and females-release $3: x^{2}<8.11, d f=5, p$ $>0.15$ ), while others showed a more varied pattern, with their distance to buildings decreased from the first to third time period but increased from fourth time period onwards (Kruskal-Wallis test, females-release 1: $x^{2}=39.27, d f=5, p<0.001$ ). On weekends, with the exception of a significant decrease in distance from the fifth to sixth time period in lone female- and females-release 3 (Kruskal-Wallis test, $x^{2}>14.38, d f=5, p \leq 0.01$; Bonferroni-Dunn Test, $p<0.05$ ), no obvious difference was seen from one time period to the next. However, all females displayed a pattern of a gradual decrease in distances over time, even though the differences were not statistically significant (Fig. 5). 


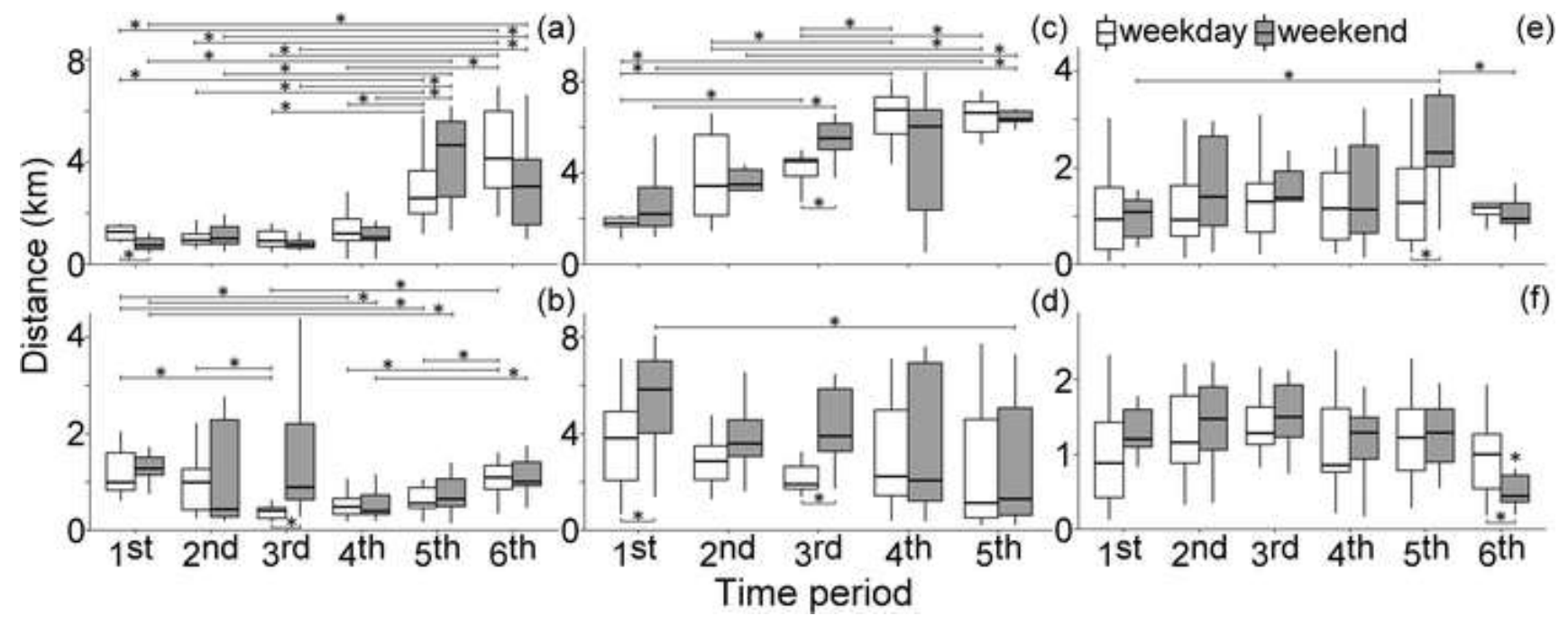

Fig. 5. Average daily distance of lions from nearest building during early post-release period in 20112012 and 2013-2014 in the Dinokeng Game Reserve, South Africa. Box plot shows median, minimum and maximum values, and first and third quartile. Asterisk indicates significant difference. a Males-release 1, $\mathbf{b}$ females-release 1, c males-release 2, $\mathbf{d}$ females-release 2, e females-release 3 and $\mathbf{f}$ lone female-release 3

\section{Utilization distribution and home range establishment}

Cumulative area of $50 \%$ core UD and $95 \%$ full UD of all lions continued to increase through the early post-release period, indicating an expansion in home range (Fig. 6). However, the rates of increase from the first to last time period differed between groups, with females-release 1 having the largest increase of both $50 \%$ core (from 0.06 to $2.71 \mathrm{~km}^{2}$ ) and $95 \%$ full UD (from 2.45 to $26.75 \mathrm{~km}^{2}$ ), while malesrelease 2 and males-release 1 had the smallest increase of $50 \%$ core (from 0.03 to $\left.0.54 \mathrm{~km}^{2}\right)$ and $95 \%$ full UD (1.82 to $\left.13.38 \mathrm{~km}^{2}\right)$, respectively, in the entire early postrelease period (Fig. 6). Although no sign of stabilization in cumulative area was detected, home range expansion appeared to slow down from fifth time period (Fig. 6). 


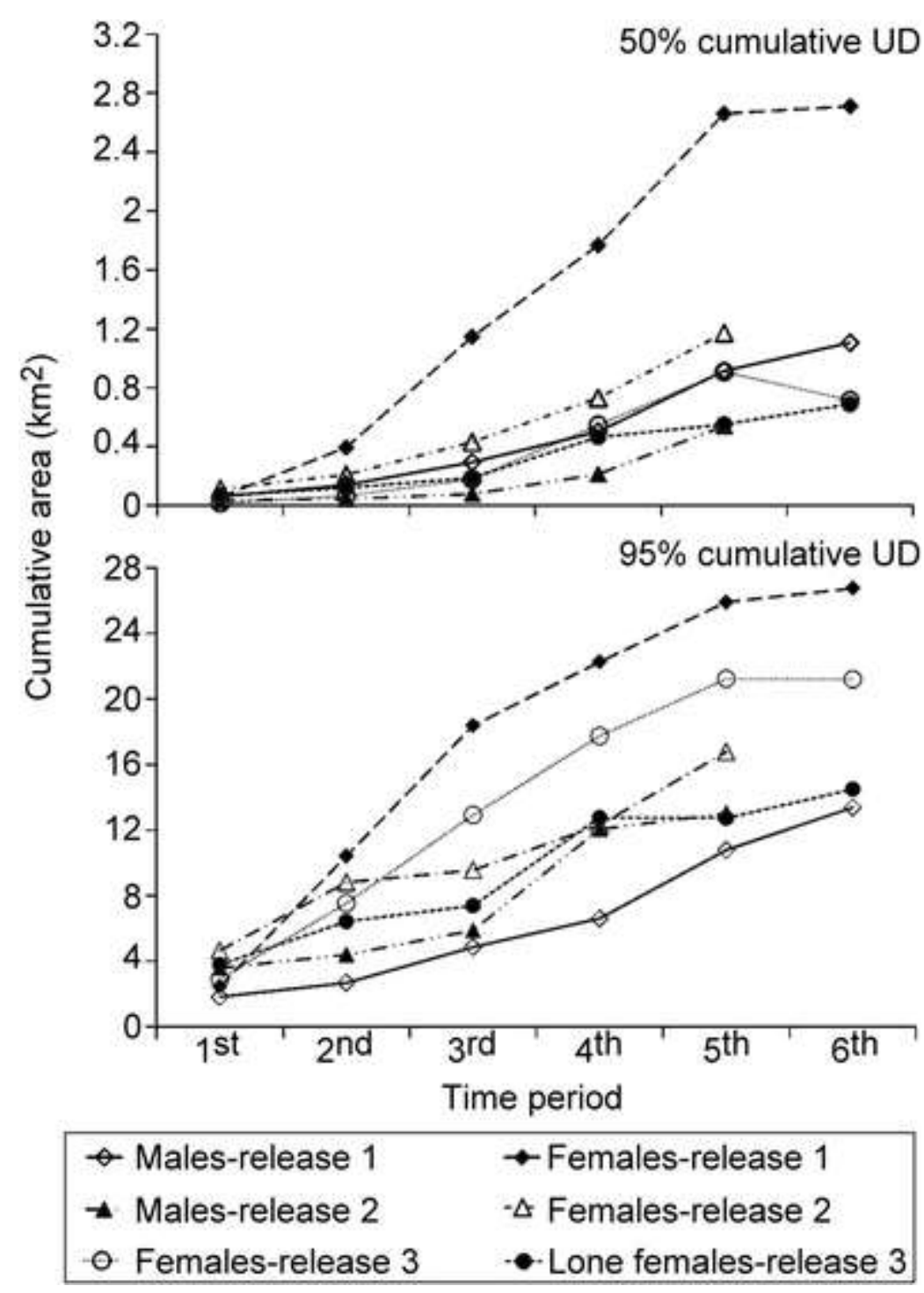

Fig. 6. Cumulative area of $50 \%$ core and $95 \%$ full utilization distribution of lions during early postrelease period in 2011-2012 and 2013-2014 in the Dinokeng Game Reserve, South Africa

\section{Discussion}

As our study shows, individual movement patterns can vary greatly between sexes and individual groups of lions. We found no evidence of homing behaviour, indicating that the animals did not reject the forced dispersal by attempting to break away from the reserve. However, the one dominant pattern in early post-release movement was that of an overwhelming variability. Even though all individuals displayed exploratory behaviour, they performed exploratory movements differently such that certain groups increased while other groups decreased their rates of movement upon release. However, changes in movement rates all occurred in either the second, third or fourth time period, and movements remained similar thereafter. Previous studies in Phinda (Hunter 1998) and Welgevonden Game Reserve (Kilian 2003) both found a general trend of increase in daily movements of reintroduced lions, but these studies were conducted only for the first 3 months of release. Results in DGR suggest that reintroduced lions might take up to 120 days in exploration before making decisions on the most cost-effective movement pattern, which then lead to stabilization of movement rates as we expected. 
Increase in rates of movement was found only in lions in the first release. In later releases, the animals had in general lower movement rates than those in the first release, and these rates either decreased or remained relatively unchanged. These differences are likely due to the fact that lions released first were at an advantage of being able to explore a competitor-free environment. As territorial carnivores, in natural populations, lions are less likely to disperse from or remain close to their natal prides during dispersal when the numbers of unrelated lions in the surrounding areas are high, as exploration in a landscape with high density of competitors could lead to territorial conflicts between groups and result in fatality (Funston et al. 2003). Without other lions to compete with, individuals released first had an opportunity to explore and establish territories with no intra-specific constraints. Low intra-specific competition also explains the general increase in movement found in Phinda Game Reserve (Hunter 1998) where lions were released in different areas and in Welgevonden Game Reserve (Kilian 2003) where there was only one release. In contrast, lions released later avoided the already released lions by having lower rates of movements and establishing home ranges that were non-overlapped with the animals released earlier (the authors, unpublished information).

After the death of one male in males-release 2, the remaining one male increased its movement during sunrise and sunset. This coincides with the behaviour observed previously in lions and other carnivores where nomadic individuals became more active diurnally to minimize interactions with dominant competitors (Hayward and Hayward 2006; Hayward and Slowtow 2009). The increase in movement might also result from the animal relocating itself more frequently to minimize the chance of being detected, as highlighted by a shift in home range of the surviving male away from its original range taken by males-release 1 after the death of the coalition member (the authors, unpublished information). Avoidance of conspecifics could also explain why lions released in the last reintroduction had similar movement rates across different time of a day, compared to lions in the first release that had the lowest rate of movement during day time throughout the study period.

Dispersal from the release sites varied between lion groups and did not coincide with changes in movement rates. This differs from the increase in distance of released lions from boma reported by Hunter (1998) and Kilian (2003) but is similar to the diverse dispersal patterns found in other translocated or reintroduced carnivores (Linnell et al. 1997; Preatoni et al. 2005). Various factors including intra-specific interactions, internal states of individuals, habitat quality and experiences in natal habitats are suggested to influence dispersal and settlement decisions of animals (Benard and McCauley 2008; Stamps et al. 2009; Santini et al. 2013). The boma in DGR is situated next to the biggest dam in the reserve (Fig. 1) which attracts different herbivores, with vegetation in the area consisting mainly of dense reed beds and riparian vegetation that are ideal for lions to ambush their prey and rest (Spong 2002). During the first release, the behaviour of lions returning to and settling in the area around the boma after initial dispersals was likely because of a preference for the reed beds after initial exploration of the environs. In fact, the core home ranges with high frequencies of revisit of the animals were centred at the dam throughout their first 3 years of release, and they were observed to hunt and rest continuously and hide their cubs in the area (the authors, unpublished information). In contrast, males in the second release dispersed continuously, while females in the same release settled in an area at least $3 \mathrm{~km}$ away from the boma after initial dispersal. 
The differences in dispersal upon release indicate that lions released later did not only move differently as mentioned before but also used the space differently in order to avoid conflicts with the lions released first. The lions released last were translocated and released in open Combretum molle vegetation in the south east side of the reserve. They then dispersed and settled 3-4 km away from the site close to rivers with floodplains and riparian vegetation, two vegetation types preferred by the lions in the study site (the authors, unpublished information) that are known to favour lions hunting (Spong 2002; De Boer et al. 2010).

The presence of buildings affected males and females differently. Upon release, males continued to move away from buildings, while females, after initial increase, generally decreased distance to building over time. Results coincide with the behaviour of reintroduced elephants in DGR that selected areas away from buildings (De Hoog 2014) and other species in several studies elsewhere that avoided human activities (Ngoprasert et al. 2007; Vanthomme et al. 2013), suggesting that human settlement was perceived as a disturbance by lions and elephants reintroduced to the reserve. While initial responses of females were to move away from buildings, the decrease in distance over time likely indicates their habituation to the disturbance which was not observed in males. Differences of distance to buildings between weekdays and weekends were found in certain time periods. DGR was still newly established with visitors and tourists consisting mainly of local people who came to visit during weekends (S-W Yiu, personal observation). Thus, higher disturbances during weekends could have contributed to the larger distances of lions to buildings in weekends than in weekdays. Differences in the number of weekend visitors staying in different lodges and residences during different times could have led to continuous changes in the intensity of disturbances and explained why lions behaved differently between time periods.

Despite the highly varied movement patterns, cumulative home ranges of all lion groups continued to increase in size over time. Space use is mostly driven by resource availability that determines the size of animal home ranges (Herfindal et al. 2005; Hayward et al. 2009). Previous studies of home ranges of reintroduced carnivores focused primarily on seasonal ranges (Hunter 1998; Druce et al. 2004), not the process of establishment and expansion of home ranges after release. Our investigation of cumulative home ranges suggests that reintroduced lions were continuously expanding their range of exploration, with different movement strategies used by different groups. Although lions expanded both core and full home ranges, their core home range remained below $3 \mathrm{~km}^{2}$ which indicate that they were able to acquire resources for survival within small areas, and the presence of fence did not impose a constraint on their movement. Hayward et al. (2009) suggested that fencing does not affect predator behaviour and home range sizes remained correlated with prey abundance in fenced reserves. DGR has high prey abundance (over 5500 herbivores excluding elephants Loxodonta africana, white rhinoceros Ceratotherium simum and hippopotamus Hippopotamus amphibius; unpublished DGR aerial census data 2012); therefore, the lions did not have to establish large home ranges to secure food. The decline in home range expansion upon the fifth time period indicates that lions begun reducing their exploration and starting to settle in the established home ranges. 
To summarize, the reintroduced lions displayed highly complex and diverse postrelease movements, where rates of movement do not necessarily correlate with spatial exploration. Optimal movement decisions of animals are to a certain extent influenced by individual ability to learn and navigate through a landscape of heterogeneous resource patches (Bélisle 2005; Roshier et al. 2008), which in DGR was shown by the varied movement patterns of different lions. As this study demonstrates, behavioural responses of lions to forced dispersal of reintroduction, their subsequent ways in exploring and adapting to a new habitat and optimal movement decisions can differ greatly between individuals, depending on intraspecific interactions, habitat preferences, human disturbances and individual experiences that vary in spatial and temporal scales. The absence of homing behaviour, stabilization in movement rates, habituation to human disturbances and decline in rates of home range expansion all together suggest release site fidelity and successful establishment of reintroduced lions. An absence of homing behaviour and a sign of stabilization in movement patterns could potentially be used as criteria for assessing early establishment success in future reintroductions. However, we show how movements can be disrupted by inter-group interactions as evidenced by the changes in movement of a male after the coalition member was killed. The behavioural differences between lions in different releases show that the presence of competitors greatly affects the exploratory movement of reintroduced animals, with intra-specific competition being the most important driver of movement decisions for those released later. Therefore, the order and release site of lion reintroductions should be planned to minimize intra-specific competition and direct conflict between groups in early establishment stages which could otherwise lead to selection of suboptimal resources and reduction in fitness.

\section{Acknowledgments}

The research was supported by The Rufford Foundation and The University of Hong Kong Postgraduate Research Travel Award. We wish to thank the Dinokeng Management Association for the permission to conduct the research and provision of satellite collars. We thank Kwalata Game Ranch, Mongena Game Lodge, Pride of Africa, Paradise Link, iKhaya LamaDube Game Lodge and landowners for their assistance in the field and for allowing the fieldwork to be undertaken in their properties. We thank Trevor Keith and Charl Pretorius for their invaluable support throughout.

\section{References}

Armstrong DP, Seddon PJ (2008) Directions in reintroduction biology. Trends Ecol Evol 23(1):20-25

Bélisle M (2005) Measuring landscape connectivity: the challenge of behavioural landscape ecology. Ecology 86(8):1988-1995

Benard MF, McCauley SJ (2008) Integrating across life-history stages: consequences of natal habitat effects on dispersal. Am Nat 171(5):553-567

Berger-Tal O, Saltz D (2014) Using the movement patterns of reintroduced animals to improve reintroduction success. Curr Zool 60(4):515-526 
Beyer HL (2004) Hawth's analysis tools for ArcGIS. Version 3.27. http://www.spatialecology.com/htools/ Accessed Jul 2011

Bonte D, Dyck HV, Bullock JM et al (2012) Costs of dispersal. Biol Rev 87:290-312

Bowler DE, Benton TG (2005) Causes and consequences of animal dispersal strategies: relating individual behaviour to spatial dynamics. Biol Rev 80(2):205-225

Calenge $C$ (2006) The package adehabitat for the R software: a tool for the analysis of space and habitat use by animals. Ecol Model 197:516-519

Cardillo M, Purvis A, Sechrest W, Gittleman JL, Bielby J, Mace GM (2004) Human population density and extinction risk in the world's carnivores. PLoS Biol 2(7), e197. doi:10.1371/journal.pbio.0020197 PubMedCentralCrossRefPubMed

de Boer WF, Vis MJP, De Knegt HJ et al (2010) Spatial distribution of lion kills determined by the water dependency of prey species. J Mammal 91(5):1280-1286

de Hoog (2014) Habitat selection of African elephants (Loxodonta africana) after reintroduction in Dinokeng Game Reserve. MSc thesis, University of the Witwatersrand, South Africa

Debeffe L, Morellet N, Cargnelutti B, Lourtet B, Coulon A, Gaillard JM, Bon R, Hewison AJM (2013) Exploration as a key component of natal dispersal: dispersers explore more than philopatric individuals in roe deer. Anim Behav 86:143-151

Delgado MM, Penteriani V, Nams VO, Campioni L (2009) Changes of movement patterns from early dispersal to settlement. Behav Ecol Sociobiol 64:35-43

Druce D, Genis H, Braak J, Greatwood S, Delsink A, Kettles R, Hunter L, Slotow R (2004) Population demography and spatial ecology of a reintroduced lion population in the Greater Makalali Conservancy, South Africa. Koedoe 47(1):103-118

Ferreira SM, Hofmeyr M (2013) Managing charismatic carnivores in small areas: large felids in South Africa. S Afr J Wildl Res 44(1):32-42

Fortin D, Beyer HL, Boyce MS, Smith DW, Duchesne T, Mao JS (2005) Wolves influence elk movements: behaviour shapes a trophic cascade in Yellowstone National Park. Ecology 86:1320-1330

Funston PJ, Mills MGL, Richardson PRK, van Jaarsveld AS (2003) Reduced dispersal and opportunistic territory acquisition in male lions (Panthera leo). J Zool 259:131-142

Getz WM, Wilmers CC (2004) A local nearest-neighbor convex-hull construction of home ranges and utilization distributions. Ecography 27:489-505

Google Earth 6.0 (2005). Accessed Jul 2013 
Hawkes C (2009) Linking movement behaviour, dispersal and population processes: is individual variation a key? J Anim Ecol 78:894-906

Hayward MW, Hayward GJ (2006) Activity patterns of reintroduced lion Panthera leo and spotted hyaena Crocuta crocuta in the Addo Elephant National Pak, South Africa. Afr J Ecol 45(2):135-141

Hayward MW, Slowtow R (2009) Temporal partitioning of activity in large African carnivores, tests of multiple hypotheses. S Afr J Wildl Res 39(2):109-125

Hayward MW, Somers MJ (eds) (2009) Reintroduction of top-order predators. Blackwell Publishing, West Sussex

Hayward MW, Adendorff J, O'Brien J et al (2007a) The reintroduction of large carnivores to the Eastern Cape, South Africa: an assessment. Oryx 41(2):205-214

Hayward MW, Adendorff J, O'Brien J et al (2007b) Practical considerations for the reintroduction of large, terrestrial, mammalian predators based on reintroductions to South Africa's Eastern Cape Province. Open Conserv Biol J 1:1-11. doi:10.2174/1874-8392/07

Hayward MW, Hayward GJ, Druce DJ, Kerley GIH (2009) Do fences constrain predator movements on an evolutionary scale? Home range, food intake and movement patterns of large predators reintroduced to Addo Elephant National Park, South Africa. Biodivers Conserv 18:887-904

Herfindal I, Linnell JDC, Odden J, Nilsen EB, Andersen R (2005) Prey density, environmental productivity and home-range size in the Eurasian lynx (Lynx lynx). J Zool 265(1):63-71

Hunter LTB (1998) The behavioural ecology of reintroduced lions and cheetahs in the Phinda Resource Reserve, Kwazulu-Natal, South Africa. PhD thesis, University of Pretoria, South Africa

Hunter LTB, Pretorius K, Carlisle LC, Rickelton M, Walker C, Slotow R, Skinner JD (2007) Restoring lions Panthera leo to northern KwaZulu-Natal, South Africa: shortterm biological and technical success but equivocal long-term conservation. Oryx 41(2):196-204

IUCN (1998) Guidelines for re-introductions. Prepared by the IUCN/SSC Reintroduction Specialist Group. IUCN, Gland

Kerley LL, Goodrich JM, Miquelle DG, Smirnov EN, Quigley HB, Hornocker MG (2002) Effects of roads and human disturbances on Amur tigers. Conserv Biol 16(1):97-108

Kilian PJ (2003) The ecology of reintroduced lions on the Welgeconden Private Game Reserve, Waterberg. MSc thesis, University of Pretoria, South Africa 
Kruskal WH, Wallis WA (1952) Use of ranks in one-criterion variance analysis. J Am Stat Assoc 47:583-621

Linnell JDC, Odden J, Smith ME (1997) Translocation of carnivores as a method for managing problem animals: a review. Biodivers Conserv 6:1245-1257

Lund U, Agostinelli C (2014) CircStats: Circular Statistics, from "Topics in circular Statistics" (2001). R package version 0.2-4. http://CRAN.R-

project.org/package $=$ CircStats

Miller SM, Funston P (2014) Rapid growth rates of lion (Panthera leo) populations in small, fenced reserves in South Africa: a management dilemma. S Afr J Wildl Res 44(1):43-55

Miller B, Ralls K, Reading RP, Scott JM, Estes J (1999) Biological and technical considerations of carnivore translocation: a review. Anim Conserv 2(1):59-68

Miller SM, Blssett C, Burger A et al (2013) Management of reintroduced lions in small, fenced reserves in South Africa: an assessment and guidelines. S Afr J Wildl Res 43(2):138-154

Morales JM, Moorcroft PR, Matthiopoulos J, Frair JL, Kie JG, Powell RA, Merrill EH, Haydon DT (2010) Building the bridge between animal movement and population dynamics. Philos Trans R Soc Lond B 365:2289-2301

Mucina L, Rutherford MC (eds) (2006) The vegetation of South Africa, Lesotho and Swaziland. Strelitzia 19, South African National Biodiversity Institute, Pretoria

New M, Lister D, Hulme M, Makin I (2002) A high-resolution data set of surface climate over global land areas. Clim Res 21:1-25

Ngoprasert D, Lynam AJ, Gale GA (2007) Human disturbance affects habitat use and behaviour of Asiatic leopard Panthera pardus in Kaeng Krachan National Park, Thailand. Oryx 41(3):343-351

Preatoni D, Mustoni A, Martinoli A et al (2005) Conservation of brown bear in the Alps: space use and settlement behavior of reintroduced bears. Acta Oecol 28:189197

R Core Team (2015) R: A language and environment for statistical computing. $R$ Foundation for Statistical Computing, Vienna, Austria. ISBN 3-900051-07-0, URL http://www.R-project.org/

Rogers LL (1988) Homing tendencies of large mammals: a review. In: Nielsen L, Brown RD (eds) Translocation of wild animals. Wisconsin Humane Society, Wisconsin, pp 76-92

Roshier DA, Doerr VAJ, Doerr ED (2008) Animal movement in dynamic landscapes: interaction between behavioural strategies and resource distributions. Oecologia 156(2):465-477 
Santini L, Marco MD, Visconti P, Baisero D, Boitani L, Rondinini C (2013) Ecological correlates of dispersal distance in terrestrial mammals. Hystrix 24(2):181-186

Seddon PJ, Armstrong DP, Maloney RF (2007) Developing the science of reintroduction biology. Conserv Biol 21(2):303-312

Spinola RM, Serfass TL, Brooks RP (2008) Survival and post-release movements of river otters translocated to western New York. Northeast Nat 15(1):13-24

Spong G (2002) Space use of lions, Panthera leo, in the Selous Game Reserve: social and ecological factors. Behav Ecol Sociobiol 52:303-307

Stamps JA, Swaisgood RR (2007) Someplace like home: experience, habitat selection and conservation biology. Appl Anim Behav Sci 102:392-409

Stamps JA, Krishnan VV, Willits NH (2009) How different types of natal experience affect habitat preferences. Am Nat 174(5):623-630

Tambling CJ, Cameron EZ, Du Toit JT, Getz WM (2010) Methods for locating African lion kills using global positioning system movement data. J Wildl Manag 73(3):549556

Tilman D, Kareiva P (eds) (1997) Spatial ecology: the role of space in population dynamics and interspecific interactions. Princeton University Press, New Jersey

Vanthomme H, Kolowski J, Korte L, Alonso A (2013) Distribution of a community of mammals in relation to roads and other human disturbances in Gabon, Central Africa. Conserv Biol 27(2):281-291

Wilmers CC, Wang Y, Nickel B, Houghtaling et al (2013) Scale dependent behavioral responses to human development by a large predator, the puma. PLoS ONE 8(4), e60590

Woodroffe R (2000) Predators and people: using human densities to interpret declines of large carnivores. Anim Conserv 3(2):165-173

Zar JH (1984) Biostatistical analysis. Prentice-Hall, New Jersey 